\title{
EVALUASI KINERJA STRUKTUR GEDUNG BETON BERTULANG METODE PUSHOVER ANALYSIS
}

\author{
Junaidin Aswar ${ }^{1}$, Johan Budianto Kromodiryo. ${ }^{1}$ \\ Fakultas Teknik, Universitas Teknologi Yogyakarta, \\ J1. Siliwangi, Jombor Lor, Sendangadi, Kec. Mlati, Daerah Istimewa Yogyakarta 55285 \\ Corresponding author : junaidinaswar@gmail.com
}

\begin{abstract}
Abstrak
Quest Hotel yang terletak di Yogyakarta merupakan bangunan bertingkat 10 lantai serta memiliki ketinggian 33,45 m. Sebuah struktur bangunan harus direncanakan sesuai dengan kaidah-kaidah perencanaan yang berlaku, sehingga dampak yang disebabkan oleh gempa dapat menahan guncangan yang telah direncanakan.Penelitian ini dilakukan dengan tujuan untuk mengetahui nilai gaya lateral maksimal serta displacement yang terjadi pada gedung dan bagaimana level kinerja berdasarkan metode FEMA 356. Besarnya gaya lateral maksimum pada arah $\mathrm{x}=8034,753 \mathrm{kN}$ pada step 9 dengan displacement sebesar $-0,042530 \mathrm{~m}$ dan pada arah y gaya lateral maksimum $=7055,847 \mathrm{kN}$ pada step 7 dengan displacement sebesar $-0,066046 \mathrm{~m}$. Hal ini menunjukan bahwa struktur gedung lebih kuat menahan gaya lateral dari arah-x dibandingkan dari arah-y. Berdasarkan hasil perhitungan analisis static non-linier, dari nilai target perpindahan maka diperoleh nilai drift aktual arah-x $=0,00484$ $(0,484 \%)$ dan nilai drift actual arah-y $=0,00773(0,73 \%)$. Hal ini menunjukkan bahwa bangunan tidak mengalami kerusakan komponen struktur. Kekuatan dan kekakuan gedung masih hampir sama dengan kondisi sebelum struktur dilanda gempa, pada keadaan ini gedung yang ditinjau adalah termasuk pada level kinerja Immediate Occupancy (IO).
\end{abstract}

Kata Kunci: Displacement, FEMA 356, Pushover, Quest Hotel.

\begin{abstract}
Quest Hotel in Yogyakarta is residential building for tourists or other people having interest in visiting Yogyakarta. This building is 10-floor building and has 33.45-m height. Design of a building structure must comply with valid design norms so that impact of earthquake could support the planned shocks. The objective of this study was to find maximum lateral force and displacement facing the buildings and performance level based on FEMA 336 method. The maximum lateral force in direction $x$ was $8034.753 \mathrm{kN}$ of step 9 with displacement = $0.042530 \mathrm{~m}$ and maximum lateral force in direction $y$ was $7055.847 \mathrm{kN}$ of step 7 with displacement $=-0.066046 \mathrm{~m}$. It indicates that the building structures are stronger to support the lateral force in direct $x$ than direction $y$. Based on the results of calculation using static non-linear analysis, displacement target value showed actual drift in direct $x=0.00484$ $(0.484 \%)$ and actual drift in direction $y=0.00773(0.73 \%)$. It indicates that the buildings did not experience the damaged structural components. The strength and rigidness of buildings were nearly similar to the previous condition before facing earthquake. In this condition, the reviewed buildings were included in performance level of Immediate Occupancy (IO).
\end{abstract}

Keywords: displacement, FEMA 356, Pushover, Quest Hotel. 
Aswar, et al

\section{PENDAHULUAN}

Provinsi D.I. Yogyakarta atau kota Yogyakarta khususnya adalah daerah wilayah rawan gempa berdasarkan peta wilayah gempa di Indonesia. Tercatat telah terjadi gempa bumi yang sangat besar mengguncang Yogyakarta pada tahun 2006 dengan kekuatan 5,9 SR MM (Magnitude Body) atau setara 6,3 SR MM (Magnitude Moment). Gempa tersebut memakan korban jiwa dengan jumlah yang sangat besar, gedung-gedung dan rumah warga hampir seluruhnya roboh yang diakibatkan oleh guncangan gempa.

Bangunan tahan gempa umumnya direncanakan dengan menggunakan prosedur yang tertulis dalam peraturan perencanaan bangunan (building codes) dilakukan dengan analisis linier (elastis), sehingga tidak menunjukkan kinerja bangunan terhadap gempa secara langsung. Oleh karena itu, perlu dilakukan evaluasi terhadap bangunan baru maupun perkuatan bangunan yang sudah ada. Salah satu trend perencanaan yang terkini yaitu menggunakan analisis beban dorong (pushover analysis). Nugroho (2016), telah melakukan penelitian mengenai evaluasi gedung di daerah rawan gempa.

Analisis pushover adalah perencanaan bangunan tahan gempa berbasis kinerja performance based seismic design, yang memanfaatkan teknik analisis non-linier berbasis komputer untuk menganalisa perilaku inelastis struktur dari berbagai macam intensitas gerakan tanah (gempa), sehingga dapat diketahui kinerjanya pada kondisi kritis, kemudian dapat dilakukan tindakan bilamana tidak memenuhi persyaratan yang diperlukan sesuai FEMA 356.

FEMA adalah singkatan dari Federal Emergency Management yang merupakan prestandart dan pendapat untuk rehabilitasi gempa bangunan yang digunakan di Amerika, dan dalam hal ini FEMA 356 merupakan aturan yang berkaitan. Kinerja struktur bangunan saat terjadi gempa dibagi menjadi beberapa kategori seperti operational, immediate occupancy, life safety.

Pada gedung Quest Hotel Yogayakarta ini yang terdiri dari 10 (sepuluh) lantai, dilakukan evaluasi kinerja terhadap gempa dengan metode Pushover Analisis sesuai FEMA 356 menggunakan program SAP2000 versi 2014. Disamping itu, standarisasi perencanaan gedung yang digunakan adalah SNI 03-1726-2012 tentang tata cara perencanaan ketahanan gempa untuk struktur bangunan gedung dan non gedung. Analisis ini diharapkan dapat menggambarkan perilaku dan tingkat kinerja (perform) dari struktur gedung Quest Hotel Malioboro, D.I. Yogyakarta.

\section{METODE PENELITIAN}

Pada penelitian ini objek yang diteliti merupakan gedung QUEST HOTEL Malioboro, Yogyakarta. Lokasi penelitian di Jalan Dagen, Malioboro, Daerah Istimewa Yogyakarta. 
Bagan alir penelitian ini dapat dilihat pada Gambar 2.1 berikut.

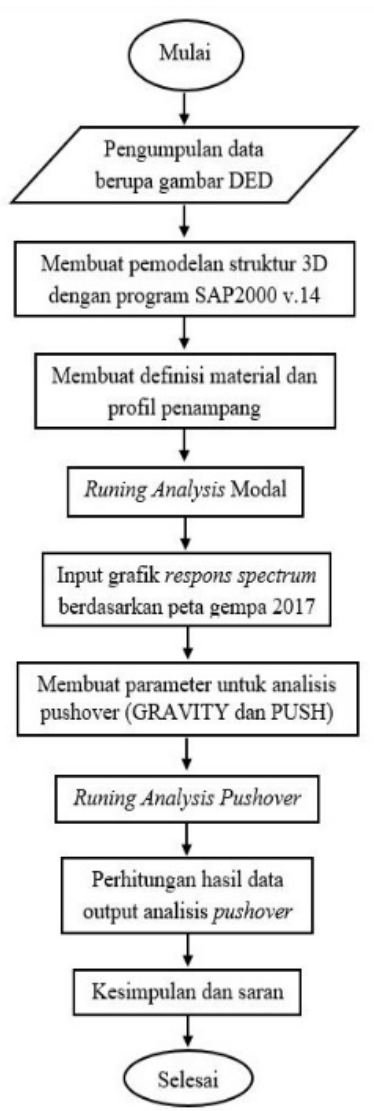

Gambar 2.1. Bagan Alir Analisis Pushover.

\section{HASIL DAN PEMBAHASAN}

\section{Data Penelitian}

Data-data gedung yang dibutuhkan guna evaluasi kinerja bangunan:

1. Fungsi Bangunan : Hotel

2. Tinggi Bangunan $: 30,25 \mathrm{~m}$

3. Tinggi basement $: 3,2 \mathrm{~m}$

4. Tinggi Lantai $1: 4 \mathrm{~m}$

5. Tinggi Lantai $2-10: 3,2 \mathrm{~m}$

6. Tinggi Lantai Mesin Lift : 0,7 m

7. Material : Beton Bertulang

8. Mutu Beton $\left(f c^{\prime}\right) \quad: 30 \mathrm{MPa}$

9. Mutu baja ulir (fy) : $400 \mathrm{MPa}$

10. Mutu baja polos $(f y): 240 \mathrm{MPa}$

\section{Perhitungan Gaya Geser}

a. Kurva Kapasitas (Capacity Curve) Kurva kapasitas (Capacity Curve) didapat melalui proses iterasi melalui proses analisis model SAP2000 V.14 Kurva kapasitas merupakan hubungan antara perpindahan titik acuan pada atap (D) dengan gaya geser dasar (V) gedung. Kurva kapasitas dapat dilihat pada Gambar 3.1 dan Gambar 3.2. Dislacement Force arah X dan Y dapat dilihat pada Tabel 3.1 dan Tabel3.2

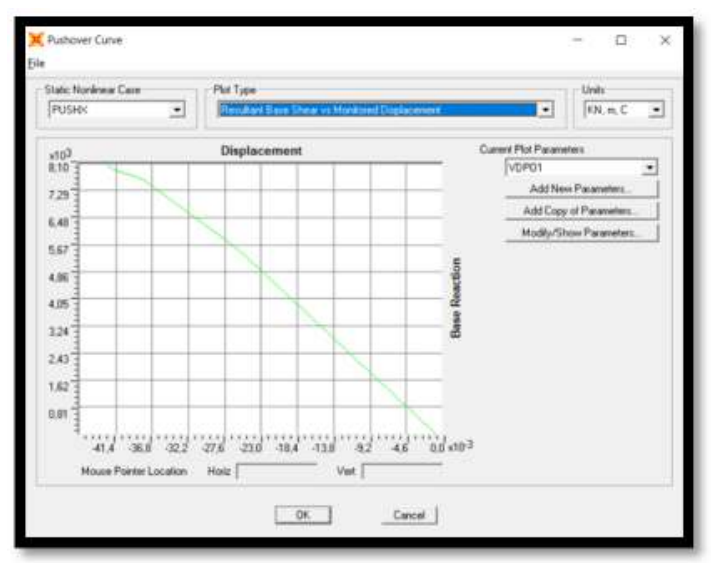

Gambar 3.1. Kurva Kapasitas Push X

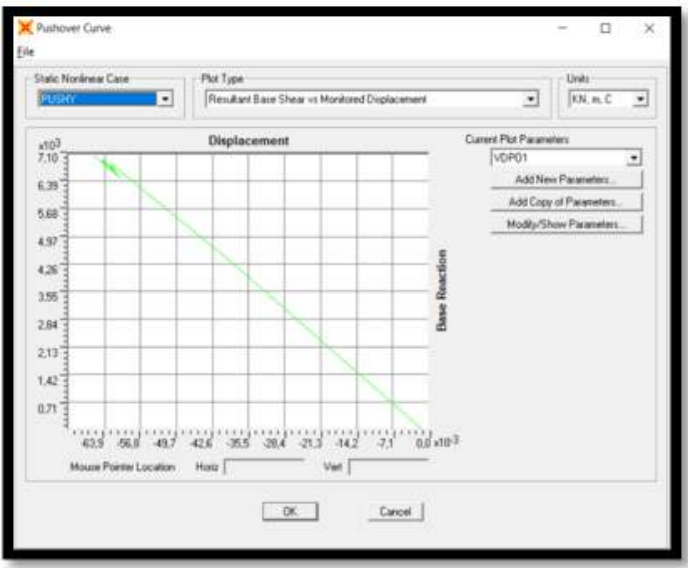

Gambar 3.2. Kurva Kapasitas Push $Y$ 
Tabel 3.1. Displacement dan Base Force-X

\begin{tabular}{|c|c|c|}
\hline Step & Displacement $(\mathrm{M})$ & BaseForce $(\mathrm{KN})$ \\
\hline 0 & 0,000800 & 0,000 \\
\hline 1 & $-0,025129$ & 5355,370 \\
\hline 2 & $-0,027045$ & 5741,339 \\
\hline 3 & $-0,027204$ & 5754,138 \\
\hline 4 & $-0,038009$ & 7619,769 \\
\hline 5 & $-0,038981$ & 7726,961 \\
\hline 6 & $-0,040189$ & 7799,429 \\
\hline 7 & $-0,041461$ & 7910,340 \\
\hline 8 & $-0,041609$ & 7913,208 \\
\hline 9 & $-0,042530$ & 8034,753 \\
\hline
\end{tabular}

(Sumber: SAP2000 v.14)

Tabel 3.2. Displacement dan Base Force-Y

\begin{tabular}{|c|c|c|}
\hline Step & Displacement $(\mathrm{M})$ & BaseForce $(\mathrm{KN})$ \\
\hline 0 & $-0,001339$ & 0.000 \\
\hline 1 & $-0,038866$ & 4318,913 \\
\hline 2 & $-0,062701$ & 6865,212 \\
\hline 3 & $-0,061793$ & 6675,482 \\
\hline 4 & $-0,064423$ & 6953,247 \\
\hline 5 & $-0,064244$ & 6905,605 \\
\hline 6 & $-0,060903$ & 6505,573 \\
\hline 7 & $-0,066046$ & 7055,847 \\
\hline
\end{tabular}

(Sumber: SAP2000 v.14)

Berdasarkan hasil perhitungan analisis pushover besarnya gaya lateral maksimum

Push-x

Gaya lateral $\max =8034,753 \mathrm{kN}$ step 9

Displacement $=-0,042530 \mathrm{~m}$ Push-y

Gaya lateral $\max =7055,847 \mathrm{kN}$ step 7

Displacement $=-0,066046 \mathrm{~m}$

Dari hasil gaya lateral maksimal dan displacement pada push-x terlihat ketika diberikan gaya yang besar yaitu 8034,753 $\mathrm{kN}$, displacement yang terjadi pada gedung hanya $-0,042530 \mathrm{~m}$. Pada push-y gaya yang bekerja terlihat lebih kecil dari push-x yaitu 7055,847 kN sedangkan displacement yang terjadi lebih besar dari pada push-x yaitu $-0,066046 \mathrm{~m}$. Hal ini menunjukan bahwa struktur gedung lebih kuat menahan gaya lateral dari arah-x dibandingkan dari arah-y.

b. Tingkat Kinerja Struktur FEMA 356

Kurva spektrum Kapasitas dapat dilihat pada Gambar 3.3 dan Gambar 3.4

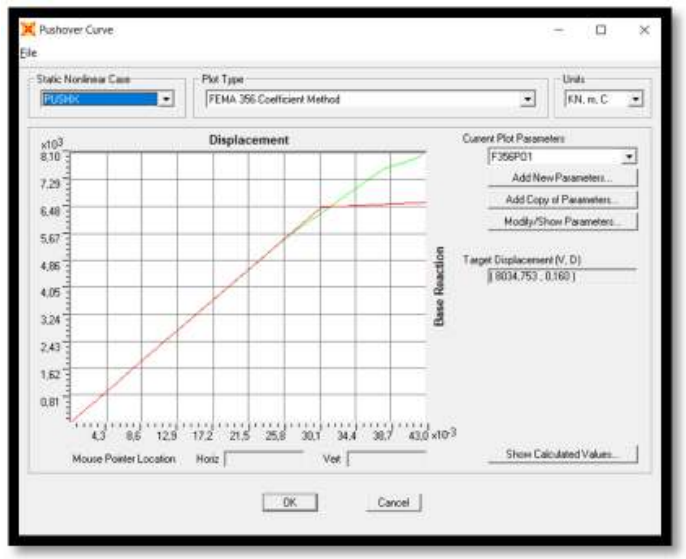

Gambar 3.3. Kurva Spektrum Kapasitas FEMA 356 Push $X$

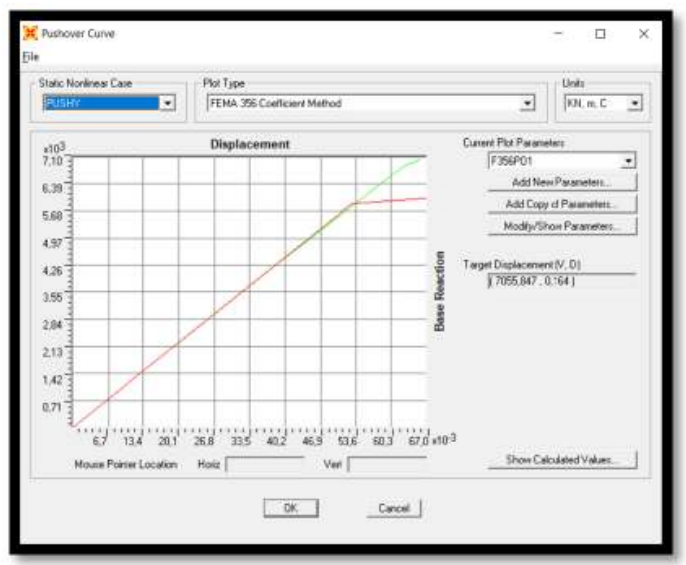

Gambar 3.4. Kurva Spektrum Kapasitas FEMA 356 Push Y 
Evaluasi Kinerja Struktur Gedung Beton Bertulang Metode Pushover Analysis

Tabel 3.3. Parameter Target Perpindahan FEMA 356 Push X dan Push Y

\begin{tabular}{|c|c|c|}
\hline & Push X & Push Y \\
\hline $\mathrm{C} 0$ & 1,7983 & 1,1148 \\
\hline $\mathrm{C} 1$ & 1,0121 & 1 \\
\hline $\mathrm{C} 2$ & 1 & 1 \\
\hline $\mathrm{C} 3$ & 1 & 1 \\
\hline $\mathrm{Sa}$ & 1,1 & 0,6965 \\
\hline $\mathrm{Te}($ detik$)$ & 0,5701 & 0,9188 \\
\hline $\mathrm{Ti}($ detik$)$ & 0,5701 & 0,9188 \\
\hline $\mathrm{Vy}(\mathrm{kN})$ & 6448,3689 & 5863,3355 \\
\hline Dy (m) & 0,160 & 0,164 \\
\hline $\mathrm{Ki}$ & 213118,5 & 111123,53 \\
\hline $\mathrm{Ke}$ & 213118,5 & 111123,53 \\
\hline $\mathrm{Alpha}$ & 0,0573 & 0,0964 \\
\hline $\mathrm{R}$ & 7,8262 & 5,4501 \\
\hline Weight & 45878,57 & 45878,57 \\
\hline $\mathrm{Cm}$ & 1 & 1 \\
\hline \multicolumn{2}{|c}{} \\
\hline
\end{tabular}

Dari hasil analisis program SAP2000 V.14 pada Tabel 3.3 maka target perpindahan dapat dihitung sebagai berikut:

a. Perhitungan $\operatorname{arah} \mathrm{X}$

$$
\begin{aligned}
\mathrm{Te} & =0,5701 \\
\mathrm{C} 0 & =1,7983 \\
\mathrm{C} 1 & =1,0121 \\
\mathrm{C} 2 & =1 \\
\mathrm{C} 3 & =1 \\
\mathrm{Sa} & =1,1
\end{aligned}
$$

Maka target perpindahan dapat dihitung:

${ }^{\delta} \mathrm{T}$

$$
\begin{aligned}
& =\mathrm{C} 0 \times \mathrm{C} 1 \times \mathrm{C} 2 \times \mathrm{C} 3 \times \mathrm{Sa} \\
& \left(\frac{T e}{2 \pi}\right)^{2} \times 9,81 \\
& =1,7983 \times 1,0121 \times 1 \times 1 \times \\
& 1,1\left(\frac{0,5701}{2 \pi}\right)^{2} \times 9,81 \\
& =0,16186 \mathrm{~m}
\end{aligned}
$$

Drift actual $=\frac{{ }^{\delta} \mathrm{T}}{\text { Htotal }}$

$$
\begin{aligned}
& =\frac{0,16186}{33,45} \\
& =0,00484 \quad(0,484 \%)
\end{aligned}
$$

b. Perhitungan $\operatorname{arah} \operatorname{arah} \mathrm{Y}$

$$
\begin{aligned}
\mathrm{Te} & =0,9188 \\
\mathrm{C} 0 & =1,1148 \\
\mathrm{C} 1 & =1 \\
\mathrm{C} 2 & =1 \\
\mathrm{C} 3 & =1 \\
\mathrm{Sa} & =0,6965
\end{aligned}
$$

Maka target perpindahan dapat dihitung :

${ }^{\delta} \mathrm{T}$

$$
\begin{aligned}
& =\mathrm{C} 0 \times \mathrm{C} 1 \times \mathrm{C} 2 \times \mathrm{C} 3 \times \mathrm{Sa} \\
& \left(\frac{T e}{2 \pi}\right)^{2} \times 9,81 \\
& =1,1148 \times 1 \times 1 \times 1 \times \\
& 1,1\left(\frac{0,9188}{2 \pi}\right)^{2} \times 9,81 \\
& =0,25843 \mathrm{~m}
\end{aligned}
$$

$$
\begin{aligned}
\text { Drift actual } & =\frac{{ }^{{ } \mathrm{T}}}{\text { Htotal }} \\
& =\frac{0,25843}{13,4} \\
& =0,00773(0,773 \%)
\end{aligned}
$$

Tabel 3.4 Hasil Perhitungan Drift Ratio Berdasarkan Perpindahan Titik Kontrol pada Saat Target Perpindahan

\begin{tabular}{|c|c|c|c|c|}
\hline $\begin{array}{c}\text { Metode } \\
\text { FEMA } \\
\mathbf{3 5 6}\end{array}$ & $\begin{array}{c}\text { Elevasi } \\
\text { Gedung } \\
\text { (m) }\end{array}$ & $\begin{array}{c}\Delta t \\
(\mathbf{m})\end{array}$ & $\begin{array}{c}\text { Drift } \\
\text { Aktual } \\
\text { (\%) }\end{array}$ & $\begin{array}{c}\text { Level } \\
\text { Kinerja } \\
\text { Gedung }\end{array}$ \\
\hline $\begin{array}{c}\text { Arah - } \\
\text { X }\end{array}$ & 33,45 & $\begin{array}{c}0,1 \\
618 \\
6\end{array}$ & 0,484 & IO \\
\hline $\begin{array}{c}\text { Arah - } \\
\text { Y }\end{array}$ & 33,45 & $\begin{array}{c}0,2 \\
584 \\
3\end{array}$ & 0,773 & IO \\
\hline
\end{tabular}

Level kinerja struktur ditentukan melalui kriteria roof drift aktual yang diperoleh pada saat target perpindahan tercapai. Berdasarkan batasan simpangan dari FEMA 356 pada Tabel 3.4, didapatkan nilai drift aktual pada arah $\mathrm{X}$ sebesar 0 , $484 \%$ berada pada level kinerja Immediate Occupancy (IO) dan nilai drift aktual pada arah Y sebesar $0,773 \%$ berada pada level kinerja Immediate Occupancy (10). 


\section{KESIMPULAN}

Setelah mengevaluasi bangunan gedung Quest Hotel Yogyakarta dengan analisis pushover menggunakan bantuan software SAP 2000 V14 maka didapatkan hasil dengan kesimpulan sebagai berikut:

a. Besarnya gaya lateral maksimum dan displacement yang terjadi berdasarkan analisis pushover menggunakanSAP2000 v14 pada gedung Quest Hotel yaitu: pada arah $\mathrm{x}$ gaya lateral maksimum $=8034,753$ $\mathrm{kN}$ pada step 9 dengan displacement sebesar $-0,042530 \mathrm{~m}$ dan pada arah y gaya lateral maksimum $=7055,847$ $\mathrm{kN}$ pada step 7 dengan displacement sebesar $-0,066046 \mathrm{~m}$.

b. Level kinerja berdasarkan FEMA 356

Berdasarkan hasil perhitungan analisis static non-linier, dari nilai target perpindahan maka diperoleh nilai drift aktual arah-x $=0,00484$ $(0,484 \%)$ dan nilai drift actual arah-y $=0,00773 \quad(0,73 \%)$. Hal ini menunjukkan bahwa bangunan tidak mengalami kerusakan komponen struktur. Kekuatan dan kekakuan gedung masih hampir sama dengan kondisi sebelum struktur dilanda gempa, pada keadaan ini gedung yang ditinjau adalah termasuk pada level kinerja Immediate Occupancy (IO).

\section{DAFTAR PUSTAKA}

Badan Standarisasi Nasional (BSN). (2012). (SNI 1726:2012) Tata Cara Perencanaan Ketahanan Gempa untuk Struktur Bangunan Gedung dan Non Gedung. Jakarta: BSN.

Federal Emergency Management Agency (FEMA 356). (1997). Prestandard and Commentary for the Seismic Rehabilitation of Buildings. Washington, D.C.: FEMA.

Nugroho, F. (2016). Evaluasi Kinerja Bangunan Gedung Berdasarkan SNI 1726-2002 dan FEMA 356 di Daerah Rawan Gempa. Jurnal Momentum Vol.18 No.1 Februari 2016. 